\title{
Characterization of Novel Edible Films and Coatings for Food Preservation Based on Gum Cordia
}

\author{
Hadi Hashemi Gahruie (D), ${ }^{1}$ Reza Safdarianghomsheh, ${ }^{1}$ Parisa Zamanifar, ${ }^{2}$ \\ Shahriyar Salehi, ${ }^{1}$ Mehrdad Niakousari $\mathbb{D}^{1},{ }^{1}$ and Seyed Mohammad Hashem Hosseini ${ }^{1}$ \\ ${ }^{1}$ Department of Food Science and Technology, School of Agriculture, Shiraz University, Shiraz, Iran \\ ${ }^{2}$ Department of Food Science, Sarverstan Branch, Islamic Azad University, Sarvestan, Fars, Iran
}

Correspondence should be addressed to Hadi Hashemi Gahruie; hadihashemigahruie@shirazu.ac.ir and Mehrdad Niakousari; mehrnia2012@yahoo.com

Received 15 July 2020; Revised 6 August 2020; Accepted 7 August 2020; Published 1 September 2020

Academic Editor: Chunpeng Wan

Copyright $(92020$ Hadi Hashemi Gahruie et al. This is an open access article distributed under the Creative Commons Attribution License, which permits unrestricted use, distribution, and reproduction in any medium, provided the original work is properly cited.

\begin{abstract}
As a pharmaceutical component, gum Cordia has been applied to improve crop resistance against many diseases. A large amount of gum appears around the fruit after soaking in an aqueous system. The mucilage possesses outstanding technofunctional properties as an emulsifier, thickening agent, and binding and stabilizing component in food and drug industries. The backbone of gum Cordia is composed of (1-2)-linked L-arabinofuranosyl and (1-6)-linked D-glucopyranosyl residues. This manuscript reviews the technofunctional properties and applications of gum Cordia in food systems. Particularly, our focus has been given to its application as a natural source for the formation of edible films and coatings for increasing the shelf life of food products and for the food preservation as a potential ingredient in formulation. The future research perspectives are also highlighted.
\end{abstract}

\section{Introduction}

Nonbiodegradable and synthetic polymeric substances are vastly used as food packaging materials that have caused significant environment concerns all over the world. Possible alternatives for plastic packaging materials are those obtained from natural and renewable resources such as polysaccharide- and protein-based films and coatings [1-4]. These films and coatings have no effect on the manufacturing process of food or its ingredients and can be readily applied as thin biopolymer layers through a wrapping or submerging process. Biopolymer-based films and coatings can be loaded with natural antioxidants and antimicrobials and other bioactive components and flavors. They are also edible, available, and biodegradable which make them a better option in comparison with synthetic materials $[5,6]$.

In contrast to synthetic and semisynthetic polymers, fruit polysaccharides are for sure vastly available, cheap in processing costs, nontoxic, biodegradable, and not dangerous to the environment, and these features make them to be applied more rather than the synthetic agrochemicals [7]. Consequently, one of the less utilized and remarkable fruits, Cordia with different species, could be a novel and potential plant source of hydrocolloids. Noteworthy, physicochemical properties of natural polymers have made them adorable and applicable for different applications in pharmaceutical and food industries [8]. Cordia is a flowering plant genus from the Boraginaceae family. This genus with almost 250 species generally grows in warm regions. C. latifolia, C. myxa, C. dichotoma, and C. abyssinia are the four species of Cordia which are considered advantageous for a number of applications in different scientific articles [9]. Cordia is found in tropical and subtropical zones of Africa, America, Oceania, and Asia [10]. The structure of gum Cordia is formed from the backbone of (1-2)-linked L-arabinofuranosyl and (1-6)-linked D-glucopyranosyl residues inside arabinoglucan formation [10]. Gum Cordia affects health positively as it has valuable nutritional compounds. Some healing aspects of gum Cordia 
TABle 1: Constitution contents and $\mathrm{pH}$ amounts related to gum Cordia.

\begin{tabular}{|c|c|c|c|c|c|c|c|}
\hline \multicolumn{8}{|c|}{ Chemical composition content (\%) } \\
\hline Moisture & $9.26[10]$ & $9.10[15]$ & & $9.1[16]$ & $8.34[17]$ & & $6.90[7]$ \\
\hline Protein & $2.47[10]$ & $2.60[15]$ & & $2.6[16]$ & $12.75[17]$ & & $8.90[7]$ \\
\hline Total carbohydrate & $78.22[10]$ & & & & & & $77.51[7]$ \\
\hline Fat & & & & & & & $1.00[7]$ \\
\hline Ash & $1.75[10]$ & $0.70[15]$ & $6.58[12]$ & $0.7[16]$ & $0.98[17]$ & $1.47[18]$ & $5.86[7]$ \\
\hline \multicolumn{8}{|l|}{ Soluble sugar } \\
\hline Uronic acid & & $8.7[15]$ & & $8.7[16]$ & $10.22[17]$ & & \\
\hline \multicolumn{8}{|l|}{$\mathrm{pH}$ and yield } \\
\hline $\mathrm{pH}$ & & & $6.5[12]$ & & & $7.2[18]$ & \\
\hline Yield (\%) & & & & $1.2[16]$ & $1.56[17]$ & & \\
\hline \multicolumn{8}{|c|}{ Mineral ion content (ppm) } \\
\hline Calcium & & & & & & & $8700[7]$ \\
\hline Phosphorus & & & & & & & $700.21[7]$ \\
\hline Potassium & & & & & & & $4.40[7]$ \\
\hline Zinc & & & & & & & $186.11[7]$ \\
\hline Iron & & & & & & & $120.97[7]$ \\
\hline
\end{tabular}

involve anti-inflammatory, astringent, antimalarial, diuretic, febrifuge, anthelminthic, cicatrizant, cough suppressant, and appetite suppressant properties and is capable of curing lung diseases, leprosy, and urinary infections. Moreover, some studies show other applications of gum Cordia such as the sustained-release matrix in the bead, nanoparticles, tablets, and microcapsules, and also utilization as an emulsifier and binder $[11,12]$.

This manuscript reviews the technofunctional features of gum Cordia in food systems. However, the main focus has been given to its application as a natural polymer for the formation of edible films and coatings to increase the shelf life of food products.

\section{Gum Cordia}

2.1. Chemical Constitution. Purity is probably the first item for identifying the properties of gums. Normally, gum Cordia includes $77-78 \%$ carbohydrate, $2.6-12.75 \%$ protein, 6.90-9.26\% moisture, $0.7-5.86 \%$ total ash, and $0-1 \%$ fat (Table 1). Carbohydrate is obviously the most abundant constituent in gum Cordia. It is more than the reported amount for gum ghatti (78.36\%) and guar gum (71.1\%) and close to the amount in the locust bean gum (85.1-88.7\%) $[13,14]$. The subtraction of other component contents of the gum from 100 equals $77.51 \%$ carbohydrate which is to a slight extent less than the total carbohydrate content acquired by the phenol sulfuric acid assay which equals $84.32 \%$. Insufficient ashing $\left(550^{\circ} \mathrm{C}\right.$ and $\left.3 \mathrm{~h}\right)$ might be the reason for this distinction. This amount of carbohydrate shows the high purity of gum Cordia. In addition, besides its purity, this gum has a good extraction efficiency that makes it a possible candidate for replacement of some commercial gums [7].

Functional properties such as stabilizing, emulsifying, and film-forming abilities could be due to the protein content inside the gum [19]. The protein fraction of gum Cordia was similar to that of the guar gum $(8.19 \%)$ and higher than that of the locust bean gum (5.2-7.4\%) and xanthan (2.125\%) [20]. Although more studies are needed, it can be considered that this gum is an emulsifier and can decrease surface tension since it has a high level of protein. The percentage of ash in gum Cordia was considerably less than that of the guar gum (11.9\%) and close to that of the xanthan gum (1.5\%), locust bean gum (0.7-1.5\%), and gum Arabic (1.2\%) [20]. It is indicated by the obtained results that the water soluble part of ash inside gum involves $3.64 \%$ of the whole ash amount which is $5.86 \%$ [7].

Methyl esterification of some uronic acid groups of gum Cordia was carried out in both ethanol and acid precipitation to $38 \%$ methoxyl content [16]. Functional features of the polysaccharide, including formation of gel, are probably affected by methoxyl groups due to the investigation of low and high methoxy pectins [21]. No starch was observed as no sample turned blue during the iodine test. This polysaccharide was almost insoluble in organic solvents and soluble in hot water with the appearance of a colloidal solution. It also had near-neutral $\mathrm{pH}$ in the form of $1 \%(\mathrm{w} / \mathrm{w})$ solution [18]. Additionally, the solution of gum Cordia has the $\mathrm{pH}$ of around neutral as well. That possibly means no irritative impact to the mucous membrane and epithelium is expected from gum Cordia in the gastrointestinal tract [22].

The mineral compounds in hydrocolloids have an impact on functional and physicochemical behaviors. For instance, the trace amount of iron ( $\mathrm{Fe})$ is destructive to the emulsifying ability of hydrocolloids [23]. Furthermore, gelforming capacity and rheological properties of polyelectrolyte hydrocolloids can be influenced by the calcium ion $\left(\mathrm{Ca}^{2+}\right)[24]$. Cadmium and some other ions with significant concentrations can cause health problems. Gum Cordia consists of $19700 \mathrm{ppm}$ potassium, $8700 \mathrm{ppm}$ calcium, 700 ppm phosphorus, $186 \mathrm{ppm}$ zinc, and $120.97 \mathrm{ppm}$ iron, but $\mathrm{Ca}$ and $\mathrm{Cu}$ concentrations did not reach the method detection limits (MDL). Table 1 shows the measured amounts of minerals. It can be found from these results that gum Cordia is rich in potassium (19700 ppm), calcium (8700 ppm), and zinc (185.93 ppm) though its copper and cadmium amounts are negligible. Gum Cordia has more valuable nutritional compounds than other commercial gums, such as guar, gum Arabic, and xanthan [25]. 
TABLE 2: Ratio of sugar composition in gum Cordia.

\begin{tabular}{lcc}
\hline & Haq et al. [9] & Benhura and chidewe [15] \\
\hline Arabinose & 11 & 9 \\
Galactose & 31 & 27 \\
Glucose & 18 & 10 \\
Mannose & 11 & 17 \\
Rhamnose & $17 \mathrm{t}$ & 21 \\
Uronic acid & 6 & 5 \\
Xylose & 6 & 11 \\
\hline
\end{tabular}

Therefore, in pharmaceutical and food science fields, gum Cordia could certainly be known as a value-added byproduct.

2.2. Carbohydrate Analysis. HPLC method was used to study sugar hydrolysates from gum Cordia. Arabinose, galactose, glucose, mannose, rhamnose, uronic acids, and xylose were traced, and in two different studies, respectively, $11: 31: 18: 11: 17: 6: 6$ [9] and $9: 27: 10: 17: 21: 5: 11$ [15] ratios were obtained. Table 2 displays the results of these analyses. As a result of inadequate digestion, it was impossible to report the absolute mass basis of hydrolysates. The data from these two studies cannot be concluded, as digestion was insufficient, and they were unlike the mentioned ratios of C. abyssinica.

2.3. Molecular Information. Functional properties of gum are remarkably affected by its molecular weight [26]. In gel permeation chromatography (GPC), gum Cordia presented a major peak, after which two small peaks appeared. Consequently, it is estimated that the formation of gum Cordia consists of three parts with different molecular weights. Haq et al. [9] observed two peaks related to gum by the GPC method, showing the average molar mass of $1.81 \times 10^{6}$ and $3.89 \times 10^{3} \mathrm{~g} \cdot \mathrm{mol}^{-1}$. Usually, the average molar mass of the first fraction in gums with a plant base is about $10^{5} \mathrm{~g} \cdot \mathrm{mol}^{-1}$, which is almost lower than the amount for gum Cordia. Gum Cordia has the average molecular weight of $2.23 \times 10^{4} \mathrm{~g} \cdot \mathrm{mol}^{-1}$ [7] that is lower than plenty of commercialized gums such as xanthan with $4.05 \times 10^{6} \mathrm{~g} \cdot \mathrm{mol}^{-1}$ [27], gellan gum with $1.64 \times 10^{6} \mathrm{~g} \cdot \mathrm{mol}^{-1}$ [28], and guar gum with $1.45 \times 10^{6} \mathrm{~g} \cdot \mathrm{mol}^{-1}$ [29]. The number average molecular weight (Mn) of gum Cordia was estimated as $1.34 \times 10^{4} \mathrm{~g} \cdot \mathrm{mol}^{-1}$. A molecular factor for understanding the molecular weight distribution and homogeneity of biopolymers is the polydispersity index $(\mathrm{PDI}=\mathrm{Mw} / \mathrm{Mn})$, which often ranges from 1.16 to 2.86 in natural polymers. Gum Cordia, with a value of 1.66 [7], had a lower PDI than lots of hydrocolloids since more uniformity was found in the gum, and on the contrary, was near to that of gum Arabic with 1.2652 and guar gum with 1.21 [30]. Unlike other gums with a plant base, such as gum Arabic $(\mathrm{PDI}=2.27)$ and kappacarrageenan $(\mathrm{PDI}=3)$, both mentioned fractions of gum Cordia had PDI of around a uniform condition value [9]. PDI expresses the heterogeneity inside chains of the polymer. Molecular mass distribution of gum Cordia is very limited, so the PDI value is about 1 . This is a desirable trait of gum that makes it favorable to be used in edible films since better tensile strength occurs in chains with homogenous structures.

2.4. Fourier-Transform Infrared Spectroscopy (FTIR). Analysis of gum Cordia by FTIR spectrometry was carried out for recognizing its functional groups. As a matter of fact, all of the usual peaks and bands related to polysaccharides can be seen in the gum spectrum [7]. At $848.2 \mathrm{~cm}^{-1}$, a noticeable shoulder represents the linkage of alpha and beta in the structure of gum [23]. Finger print area (from 1000 to $1200 \mathrm{~cm}^{-1}$ ) is a region in which any polysaccharide shows a particular behavior. This area explains the distinctions in structures of biopolymers. The signal at $1030 \mathrm{~cm}^{-1}$ is related to uronic acid. There are some peaks in the range of 950 to $1200 \mathrm{~cm}^{-1}$ as a result of the stretching vibration associated with alcoholic $\mathrm{CO}$ in $\mathrm{COH}$ bands inside carbohydrates [22]. The observed peak at $1635 \mathrm{~cm}^{-1}$ shows valence vibration and carboxyl groups. Gel-forming ability and viscosity could be affected by possible interactions between some ions, such as calcium and carboxyl groups [31]. Carboxylic ester causes the wavenumber near $1737 \mathrm{~cm}^{-1}$. The small peak at $2921.91 \mathrm{~cm}^{-1}$ expresses the stretching vibration of C-H related to the methylene group. Double overlapping with hydroxyl groups might cause this peak as well. The peak at $3438.81 \mathrm{~cm}^{-1}$ is related to the stretching vibration of O-H. Hydrogen bonding of the hydroxyl groups inside glucopyranose rings is also associated with this enormous peak [32].

\subsection{Differential Scanning Calorimetry (DSC). Differential} scanning calorimetry (DSC) uses temperature for tracking the obtained or lost heat in samples, during chemical and physical changes. Impurities are explained by wide asymmetric curves which could also be the sign of two or more thermal processes, and relative purity is described by an obvious symmetric peak of the melting endotherm [18]. Phase transitions in polymers are commonly investigated by DSC since it is a very precise and sensitive method. Occurrence of changes in the main chain during heating causes two endothermic behaviors in the DSC thermogram of gum Cordia. The first endothermic reaction of gum Cordia happened as a result of bound and free water loss, and a vast peak appeared around $147^{\circ} \mathrm{C}$ which is the glass transition temperature $\left(T_{g}\right)$. Decomposition or melting of gum at $238^{\circ} \mathrm{C}$ (melting temperature or $T_{m}$ ) brings up the second endothermic reaction and provokes a little peak at the related temperature. It can be found that although gum Cordia looks crystalline, it has an amorphous characteristic, considering its wide DSC thermogram. In the industry (production and storage stages), it is important to have information about the glass transition temperature and the items that have impact on it, such as additives and moisture that change the formation of molecules and consequently simplify the transformation to the crystalline or rubbery phase [32]. In different studies, low crystallinity was observed for substances with a low glass transition temperature [22]. 
2.6. X-Ray Diffraction (XRD). Remarkable peaks of gum Cordia appear of the order of $2 \theta$ which equals $26^{\circ}, 29^{\circ}, 30^{\circ}$, and $5^{\circ}$. Meanwhile, uncertain and very small peaks and also shoulder forms stuck to other strong peaks can be seen. XRD data estimate the occurrence of both crystalline and amorphous forms in gum Cordia, which confirms the results of DSC [18].

\section{Applications}

3.1. Biodegradable Edible Films. The quick increase in the production rate of nondegradable petroleum-based plastic materials causes serious environmental concerns [33]. Therefore, many efforts have been made to find environmentally friendly materials. Natural polymers (proteins and polysaccharides) have received much attention due to biodegradability [17]. One of the important applications of gum Cordia is the production of edible films. Haq et al. [34] studied the properties of the edible gum Cordia film with added beeswax. Beeswax affected the film by decreasing its elongation at break, tensile strength, and Young's modulus. Gum Cordia films with beeswax had a water vapor permeability of $0.06-0.33 \times 10^{-10} \mathrm{~g} \cdot \mathrm{m}^{-1} \cdot \mathrm{s}^{-1} \cdot \mathrm{Pa}^{-1}$, which is lower than that of the control films. Additionally, it is found that oxygen permeability becomes greater from 0.39 to $18.73 \mathrm{~g} \cdot \mathrm{m}^{-1} \cdot \mathrm{s}^{-1} \cdot \mathrm{Pa}^{-1}$ in a beeswax concentration of $0.05 \mathrm{~g} \cdot \mathrm{g}^{-1}$. Nevertheless, oxygen permeability stopped increasing as beeswax reached higher concentrations. Results obtained from this work will draw attentions to Cordia as a plentiful source of gum and ease its applications. Further progression is also expected in edible packaging made from gum Cordia, for fresh material coating, specifically. Haq et al. [35] analyzed the attributes of the edible gum Cordia film affected by plasticizers. Edible gum Cordia films were made considering the concentration and kind of the plasticizer and then their permeability to gas, and also their rheological and thermal characteristics were studied. The solution casting method was carried out for production of the films. Chosen plasticizers were PEG (polyethylene glycol) 200, PEG 400, sorbitol, and glycerol for an amount of 0.1 to $0.3 \mathrm{~g} \cdot \mathrm{g}^{-1}$ dry polymer weight basis. It was indicated that film behaviors rely on the concentration and nature of the plasticizer. Gum and plasticizers had interactions which were recognized by FTIR spectroscopy. Miscibility of gum and plasticizers was estimated by DSC. The glass transition temperature was observed inside the range of -66 to $-11^{\circ} \mathrm{C}$. From the rheological point of view, these films had elongation at break of more than $10 \%$ and tensile strength of higher than $10 \mathrm{MPa}$. Glycerol, sorbitol, PEG 200, and PEG 400 caused the most remarkable tensile changes, respectively. Water vapor permeability was measured from 0.91 to $5.5 \times 10^{-10} \mathrm{~g} \cdot \mathrm{m}^{-1} \cdot \mathrm{s}^{-1} \cdot \mathrm{Pa}^{-1}$. Oxygen permeability was obtained in range of 0.16 to $5.31 \times 10^{-15} \cdot \mathrm{g} \cdot \mathrm{m}^{-1} \cdot \mathrm{s}^{-1} \cdot \mathrm{Pa}^{-1}$. Edible film could be prepared by the casting method from gum Cordia added with various plasticizers. Modification of these films is possible by using different plasticizers and their various concentrations. Miscibility and interactions between plasticizers and gum were observed in the produced films. Addition of glycerol, sorbitol, PEG 200, and PEG 400 to gum
Cordia films, respectively, was responsible for higher induced elongation at break and tensile strength. Adding PEG 400 can also hold the oxygen permeability in a lower amount. This research announces Cordia as a plant with simple uses in the mentioned area and gives hope for improvement of edible packaging. Haq et al. [36] reported that plasticizers have an impact on optical and sorption characteristics of edible gum Cordia films. The goal was to identify the biodegradable film made from the extracted gum of plant Cordia. PEG200, PEG 400, sorbitol, and glycerol were used as plasticizers with concentrations of 0 to $30 \%$ to investigate their influence on optical and sorption behaviors of the casted film. The results of this analysis corresponded to the type II isotherm, according to the GAB model of sorption since the equilibrium moisture content of films increased by increasing the concentration of plasticizers. Increasing the concentration of the plasticizer also increased the value of the monolayer, as the most effective one was glycerol with $0.93 \mathrm{~g} \cdot \mathrm{g}^{-1}$. Total color difference $(\Delta E)$ was enhanced as more plasticizers were added, and glycerol had the most impact again. All samples resisted 200 to $280 \mathrm{~nm}$ wavelength of UV spectra. A comparative film with more desirable characteristics for edible coating applications could be made from Cordia myxa fruit gum. Plasticizers along with anionic Cordia gum create the film. In comparison with typically used edible films, this one involved more preferable optical properties and sorption isotherms. Each plasticizer was tested in terms of its concentration to indicate its efficacy, and it became clear that glycerol was the most effective. By applying the GAB equation, sigmoidal curves of isotherms related to gum Cordia films could be drawn. Water molecules bond to sorption sites of gum by a lower rate since plasticizers reduce the needed energy for this action. The total color of the gum Cordia film was also lowered by presence of plasticizers. Incorporation of gum Cordia with every plasticizer produced transparent films. But, the UV spectrum could not pass through these films easily.

3.2. Coating Applications. Application of gum Cordia as a coating especially for nuts was reported in various research studies. El-Mogy et al. [37] investigated the impact of gum Cordia on the postharvest quality of fresh artichoke bottoms. Results showed that the addition of ascorbic acid or $\mathrm{CaCl}_{2}$ to gum Cordia-based edible coatings improves the amount of total phenolic compounds and vitamin $\mathrm{C}$ and prevents the weight loss. Gum Cordia incorporated with ascorbic acid considerably inhibited polyphenol oxidase and browning activities. Gum Cordia-free $\mathrm{CaCl}_{2}$ solution reduced the count of psychrotrophic and mesophilic bacteria. The strongest treatment against $E$. coli and molds was the combination of $\mathrm{CaCl}_{2}$ and gum Cordia. Therefore, a mixture of gum Cordia and $\mathrm{CaCl}_{2}$ was suggested as a proper coating for artichoke bottoms during postharvest storage. More research studies are needed for the commercial application of gum Cordia in preserving fresh-cut artichoke bottoms. Haq et al. [38] studied potentials of gum Cordia to prevent oxidation of lipids in peanuts as an antioxidant carrier. 
Attachment to the polymer matrix (e.g., edible films with a gum base) enhances the efficiency of antioxidants. Good emulsification and adhesion capabilities of gum Cordia make it a possible carrier for antioxidants. The purpose of this investigation was to inspect the capacities of gum Cordia for coating peanuts in the form of an antioxidant carrier. Antioxidants for delivery action included vitamin C, BHA (butylated hydroxyanisole), and BHT (butylated hydroxytoluene) used in a comparison between gum Cordia and carboxymethyl cellulose as carriers. Carrier efficiency of two gums was compared by analyzing the oxidized flavor, thiobarbituric acid-reactive species, and peroxide value of uncoated and coated peanuts which were kept at $35^{\circ} \mathrm{C}$ for 126 days. Uncoated and coated peanuts showed significant differences $(p<0.05)$. Gum Cordia was a better carrier in antioxidant delivery. According to the peroxide value $\left(40^{\circ}\right.$ meq of $\left.\mathrm{O}_{2} \mathrm{~kg}^{-1}\right)$, gum Cordia with BHA/BHT $(290 \%$ more shelf life than the uncoated sample), gum Cordia with BHT (244\%), gum Cordia with BHA (232\%), carboxymethyl cellulose with BHA/BHT (184\%), carboxymethyl cellulose with BHA (139\%), carboxymethyl cellulose with BHT (119\%), gum Cordia with vitamin C (96\%), and carboxymethyl cellulose with vitamin C (46\%) fulfilled carrier responsibility, respectively. Therefore, it is clear that gum Cordia acts as a capable carrier for antioxidants and probably other functional stuffs in the form of edible coating. Other conditions are being studied for more advances in using this gum as a coating film. Abdul Haq et al. [39] carried out assessments to improve the shelf life of Pinus gerardiana by gum Cordia edible coating. Anionic gum of Cordia is the reason for its good adhesion ability. Pinus gerardiana is full of unsaturated fatty acids which makes its unshelled nuts vincible to oxidation. Carboxymethyl cellulose and gum Cordia were compared in terms of preventing rancidity of Pinus gerardiana in the form of edible coatings. Carboxymethyl cellulose and gum Cordia each included a free sample and a sample containing natural antioxidants. Studied antioxidants were $\alpha$-tocopherol and the methanolic extract of Cordia myxa. Sensory and chemical analyses were carried out on all samples (coated and uncoated) which were kept at $35^{\circ} \mathrm{C}$ for 112 days. Uncoated and coated nuts demonstrated significant differences $(p<0.05)$. In accordance with the peroxide value ( 20 meq of $\mathrm{O}_{2} \mathrm{~kg}^{-1}$ ), samples involving gum Cordia with the added extract of Cordia myxa, carboxymethyl cellulose with the added Cordia myxa extract (circa 60\%), free gum Cordia (circa 25\%), and free carboxymethyl cellulose (circa 15\%) showed the most effectiveness, respectively. $\alpha$-Tocopherol did not exhibit any impact on nuts. Consequently, gum Cordia could act as a potent natural edible film for inducing higher shelf life in pine nuts. This gum might also be an option in other foods for increasing shelf life and invincibility to rancidity by its coating capability. Haq and Hasnain [40] studied gum Cordia coating with involvement of antioxidants to prevent rancidity of peanuts. Abilities of two gums, i.e., gum Cordia and carboxymethyl cellulose, in improving shelf life of peanuts were compared. Samples of both free and with natural antioxidants of carboxymethyl cellulose and gum Cordia were investigated. $\alpha$-Tocopherol and the methanolic extract of the Cordia myxa fruit were the present antioxidants. Peanuts were held at $35^{\circ} \mathrm{C}$ for 126 days, and their sensory and chemical properties were analyzed. By considering the peroxide value $\left(40\right.$ meq $\left.\mathrm{O}_{2} \mathrm{~kg}^{-1}\right)$, gum Cordia having the Cordia myxa extract showed $122 \%$, free gum Cordia showed 91\%, carboxymethyl cellulose having the Cordia myxa extract showed $80 \%$, and free carboxymethyl cellulose showed $70 \%$ growth in shelf life of samples. No beneficial effect was induced by $\alpha$-tocopherol. It is estimated that increasing shelf life of peanuts is possible by gum Cordia coating although no information exists about its mechanism of action. More studies are being done for a better understanding of the physicochemical attributes of edible gum Cordia coatings. Foods with a high lipid content could be the targets of this natural coating for increasing their shelf life.

\section{Conclusion}

This review article, which is based on the findings of the studies on gum Cordia, demonstrates that the gum Cordia may be used to improve the viscoelastic, textural, stability, and other parameters of foods and drugs. It can be applied to create novel applications such as encapsulation and delivery of bioactive ingredients. These beneficial properties suggest this gum as a proper component which could potentially be used for different purposes in pharmaceutical and food products. But, still more research is needed to find the chemical structure and other important technofunctional characterization of gum Cordia. This gum may be of technological importance and can be used for the improvement of food product quality.

More research works are required to be carried out in the field of modified processing methods and isolation and purification techniques. Structure-function relationship elucidation and backbone-directed chemical modification of gum Cordia might expand its applications in the food industry.

\section{Data Availability}

The data used to support the study are included within the article. Any more information can be obtained by contacting the corresponding author.

\section{Conflicts of Interest}

The authors declare that they have no conflicts of interest.

\section{Acknowledgments}

This work was financially supported by Shiraz University (Grant no. 96GCU5M194065).

\section{References}

[1] W. Zam, "Effect of alginate and chitosan edible coating enriched with olive leaves extract on the shelf life of sweet cherries (Prunus avium L.)," Journal of Food Quality, vol. 2019, Article ID 8192964, 7 pages, 2019. 
[2] V. Farina, R. Passafiume, I. Tinebra et al., "Postharvest application of aloe vera gel-based edible coating to improve the quality and storage stability of fresh-cut papaya," Journal of Food Quality, vol. 2020, Article ID 8303140, 10 pages, 2020.

[3] X. Carrión-Granda, I. Fernández-Pan, J. Rovira, and J. Maté, "Effect of antimicrobial edible coatings and modified atmosphere packaging on the microbiological quality of cold stored hake (Merluccius merluccius) fillets," Journal of Food Quality, vol. 2018, Article ID 6194906, 12 pages, 2018.

[4] W. Liu, Y. Shen, N. Li, J. Mei, and J. Xie, "Application of gelatin incorporated with red pitaya peel methanol extract as edible coating for quality enhancement of crayfish (Procambarus clarkii) during refrigerated storage," Journal of Food Quality, vol. 2019, Article ID 1715946, 8 pages, 2019.

[5] H. Hashemi Gahruie, M. Mostaghimi, F. Ghiasi, S. Tavakoli, M. Naseri, and S. M. H. Hosseini, "The effects of fatty acids chain length on the techno-functional properties of basil seed gum-based edible films," International Journal of Biological Macromolecules, vol. 160, pp. 245-251, 2020.

[6] H. H. Gahruie, M. H. Eskandari, M. Khalesi, P. Van der Meeren, and S. M. H. Hosseini, "Rheological and interfacial properties of basil seed gum modified with octenyl succinic anhydride," Food Hydrocolloids, vol. 101, p. 105489, 2020.

[7] S. Keshani-Dokht, Z. Emam-Djomeh, M.-S. Yarmand, and M. Fathi, "Extraction, chemical composition, rheological behavior, antioxidant activity and functional properties of Cordia myxa mucilage," International Journal of Biological Macromolecules, vol. 118, pp. 485-493, 2018.

[8] C. Malsawmtluangi, K. Thanzami, H. Lalhlenmawia et al., "Physicochemical characteristics and antioxidant activity of Prunus cerasoides D. Don gum exudates," International Journal of Biological Macromolecules, vol. 69, pp. 192-199, 2014.

[9] M. A. Haq, A. Hasnain, K. Jamil, and M. S. Haider, "Extraction and characterization of gum from Cordia myxa," Asian Journal of Chemistry, vol. 26, no. 1, pp. 122-126, 2014.

[10] M. Chaharlang and V. Samavati, "Steady shear flow properties of Cordia myxa leaf gum as a function of concentration and temperature," International Journal of Biological Macromolecules, vol. 79, pp. 56-62, 2015.

[11] M. Ahuja, S. Kumar, and A. Kumar, "Evaluation of mucoadhesive potential of gum cordia, an anionic polysaccharide," International Journal of Biological Macromolecules, vol. 55, pp. 109-112, 2013.

[12] V. Doharey, N. Sharma, and M. Bindal, "Assessment of the suspending properties of Cordia gheraf gum on paracetamol suspension," Scholars Research Library, vol. 2, pp. 510-517, 2010.

[13] V. M. Busch, A. A. Kolender, P. R. Santagapita, and M. P. Buera, "Vinal gum, a galactomannan from Prosopis ruscifolia seeds: physicochemical characterization," Food Hydrocolloids, vol. 51, pp. 495-502, 2015.

[14] J. Kang, Q. Guo, Q. Wang, G. O. Phillips, and S. W. Cui, "New studies on gum ghatti (Anogeissus latifolia) part 5: the conformational properties of gum ghatti," Food Hydrocolloids, vol. 43, pp. 25-30, 2015.

[15] M. A. N. Benhura and C. Chidewe, "Some properties of a polysaccharide preparation that is isolated from the fruit of Cordia abyssinica," Food Chemistry, vol. 76, no. 3, pp. 343-347, 2002.

[16] M. Benhura and C. Chidewe, "Characterization of the polysaccharide material that is isolated from the fruit of
Cordia abyssinica," African Journal of Biochemistry Research, vol. 5, pp. 95-101, 2011.

[17] H. Hashemi Gahruie, E. Ziaee, M. H. Eskandari, and S. M. H. Hosseini, "Characterization of basil seed gum-based edible films incorporated with Zataria multiflora essential oil nanoemulsion," Carbohydrate Polymers, vol. 166, pp. 93-103, 2017.

[18] H. A. Pawar and P. Jadhav, "Isolation, characterization and investigation of Cordia dichotoma fruit polysaccharide as a herbal excipient," International Journal of Biological Macromolecules, vol. 72, pp. 1228-1236, 2015.

[19] M. Fathi, M. Mohebbi, and A. Koocheki, "Introducing Prunus cerasus gum exudates: chemical structure, molecular weight, and rheological properties," Food Hydrocolloids, vol. 61, pp. 946-955, 2016.

[20] P. A. Dakia, C. Blecker, C. Robert, B. Wathelet, and M. Paquot, "Composition and physicochemical properties of locust bean gum extracted from whole seeds by acid or water dehulling pre-treatment," Food Hydrocolloids, vol. 22, no. 5, pp. $807-818,2008$.

[21] L. Barnavon, T. Doco, N. Terrier, A. Ageorges, C. Romieu, and P. Pellerin, "Involvement of pectin methyl-esterase during the ripening of grape berries: partial cDNA isolation, transcript expression and changes in the degree of methyl-esterification of cell wall pectins," Phytochemistry, vol. 58, no. 5, pp. 693-701, 2001.

[22] H. A. Pawar, A. J. Gavasane, and P. D. Choudhary, "Extraction of polysaccharide from fruits of Cordia dichotoma G. Forst using acid precipitation method and its physicochemical characterization," International Journal of Biological Macromolecules, vol. 115, pp. 871-875, 2018.

[23] M. H. Sherahi, M. Fathi, F. Zhandari, S. M. B. Hashemi, and A. Rashidi, "Structural characterization and physicochemical properties of Descurainia sophia seed gum," Food Hydrocolloids, vol. 66, pp. 82-89, 2017.

[24] L. Pachuau, H. Lalhlenmawia, and B. Mazumder, "Characteristics and composition of Albizia procera (Roxb.) benth gum," Industrial Crops and Products, vol. 40, pp. 90-95, 2012.

[25] W. Cui and G. Mazza, "Physicochemical characteristics of flaxseed gum," Food Research International, vol. 29, no. 3-4, pp. 397-402, 1996.

[26] B. Yang, Y. Jiang, M. Zhao, J. Shi, and L. Wang, "Effects of ultrasonic extraction on the physical and chemical properties of polysaccharides from longan fruit pericarp," Polymer Degradation and Stability, vol. 93, no. 1, pp. 268272, 2008.

[27] Y. Viturawong, P. Achayuthakan, and M. Suphantharika, "Gelatinization and rheological properties of rice starch/ xanthan mixtures: effects of molecular weight of xanthan and different salts," Food Chemistry, vol. 111, no. 1, pp. 106-114, 2008.

[28] G. Sworn and S. Kasapis, "Effect of conformation and molecular weight of co-solute on the mechanical properties of gellan gum gels," Food Hydrocolloids, vol. 12, no. 3, pp. 283-290, 1998.

[29] H. A. Khouryieh, T. J. Herald, F. Aramouni, and S. Alavi, "Intrinsic viscosity and viscoelastic properties of xanthan/ guar mixtures in dilute solutions: effect of salt concentration on the polymer interactions," Food Research International, vol. 40, no. 7, pp. 883-893, 2007.

[30] J. Milani, B. Ghanbarzadeh, and G. Maleki, "Rheological properties of anghouzeh gum," International Journal of Food Engineering, vol. 8, no. 3, 2012. 
[31] S. M. A. Razavi, S. W. Cui, Q. Guo, and H. Ding, "Some physicochemical properties of sage (Salvia macrosiphon) seed gum," Food Hydrocolloids, vol. 35, pp. 453-462, 2014.

[32] O. P. Troncoso, B. Zamora, and F. G. Torres, "Thermal and rheological properties of the mucilage from the fruit of Cordia lutea," Polymers from Renewable Resources, vol. 8, no. 3, pp. 79-90, 2017.

[33] H. Hashemi Gahruie, M. H. Eskandari, P. Van der Meeren, and S. M. H. Hosseini, "Study on hydrophobic modification of basil seed gum-based (BSG) films by octenyl succinate anhydride (OSA)," Carbohydrate Polymers, vol. 219, pp. 155$161,2019$.

[34] M. A. Haq, A. Hasnain, F. A. Jafri, M. F. Akbar, and A. Khan, "Characterization of edible gum cordia film: effects of beeswax," LWT-Food Science and Technology, vol. 68, pp. 674-680, 2016.

[35] M. A. Haq, A. Hasnain, and M. Azam, "Characterization of edible gum cordia film: effects of plasticizers," LWT-Food Science and Technology, vol. 55, no. 1, pp. 163-169, 2014.

[36] M. A. Haq, F. A. Jafri, and A. Hasnain, "Effects of plasticizers on sorption and optical properties of gum cordia based edible film," Journal of Food Science and Technology, vol. 53, no. 6, pp. 2606-2613, 2016.

[37] M. M. El-Mogy, A. Parmar, M. R. Ali, M. E. Abdel-Aziz, and E. A. Abdeldaym, "Improving postharvest storage of fresh artichoke bottoms by an edible coating of Cordia myxa gum," Postharvest Biology and Technology, vol. 163, Article ID 111143, 2020.

[38] M. A. Haq, M. Azam, and A. Hasnain, "Gum cordia as carrier of antioxidants: effects on lipid oxidation of peanuts," Journal of Food Science and Technology, vol. 52, no. 4, pp. 2366-2372, 2015.

[39] M. Abdul Haq, M. Junaid Alam, and A. Hasnain, "Gum Cordia: a novel edible coating to increase the shelf life of Chilgoza (Pinus gerardiana)," LWT-Food Science and Technology, vol. 50, no. 1, pp. 306-311, 2012.

[40] M. A. Haq and A. Hasnain, "Antioxidant containing gum cordia coatings for control of peanut oxidation," Journal of Food Processing and Preservation, vol. 38, no. 3, pp. 896-904, 2014. 